\title{
BUILDING BACK BETTER WITH VULNERABILITY: POST-HAIYAN REFLECTIONS ON RISK PERCEPTION
}

\author{
MICHIKO BANBA ${ }^{1}$, MARIA MAKABENTA IKEDA ${ }^{2}$, MAYUMI SAKAMOTO ${ }^{1} \&$ YOSHIKI TOMINAGA $^{1}$ \\ ${ }^{1}$ University of Hyogo, Japan \\ ${ }^{2}$ Kyoto Sangyo University, Japan
}

\begin{abstract}
Several studies show that the lack of information about the scale of disaster risks contributed to the increased vulnerability of many people affected by Typhoon Haiyan in 2013. A conceptual framework based on the behavioural intention model is used to examine how demographic attributes, experience of disaster occurrence, knowledge about natural hazards and community-based disaster risk reduction efforts affect disaster risk perception. We analyse how effective disaster knowledge and community efforts are in raising risk awareness and influencing risk reduction behaviour. A questionnaire survey is conducted among households living in the cities of Tacloban, Palo and Tanauan, located along the north-eastern coast of Leyte, Philippines. Using structural equation modelling (SEM), we empirically test hypotheses on risk perception and behavioural intention to reduce disaster risk using data from 282 households. We attempt to investigate how risk perception and risk reduction behaviour are affected by two elements that we think can be potentially harnessed for sustainability of the build-back-better process: (a) knowledge about disasters and (b) community efforts. Our results show model compatibility for the variables (1) disaster experience, (2) risk perception and (3) knowledge about natural hazards. On the other hand, we find weak model compatibility for the variables (1) disaster education and (2) community efforts.
\end{abstract}

Keywords: disaster risk reduction, knowledge, risk perception, behavioural intention model, adaptive behaviour, intention, disaster education, community, vulnerability, resilience.

\section{INTRODUCTION}

Typhoon Haiyan in 2013 exacted a severe toll both in economic damages and human lives throughout Leyte Island in the Philippines (Table 1).

The possibility of recurrence of strong typhoons like Typhoon Haiyan is more likely than estimates of once in 100 years due to climate change. Thus, people should not underestimate extreme weather and potential disaster impacts. In order to reduce disaster risks, building capacities of people and resilient communities through modules of self-help, mutual assistance and public-private partnership initiatives is essential.

Even after a major disaster like Haiyan, it is not easy to raise the disaster risk awareness of people and conduct community efforts for disaster risk reduction during normal or calm conditions. Although preparation for disaster should be made before another serious disaster occurs, people need constant reminders to engage in protective behaviour. Essential to an ideal disaster preparedness program as well as the build-back-better reconstruction of post-Haiyan Leyte is the regular dissemination of disaster awareness information and conduct of community disaster drills. This study focuses on the importance of understanding the factors affecting risk perception or psychological mechanisms that influence the performance or non-performance of broad-based disaster preparedness and risk reduction efforts by people living in post-Haiyan Leyte.

Quite a few studies have analysed the differences of psychological mechanisms affecting risk perception and disaster risk reduction. In particular, we studied concepts related to the Theory of Planned Behaviour and Theory of Reasoned Action [2], [3]. According to these 
Table 1: Top 10 natural disasters and number of deaths, Philippines 1970-2018. (Source: EM-DAT [1].)

\begin{tabular}{|l|c|c|}
\hline Popular name/Type of Hazard & Date of event & Total number of deaths \\
\hline Typhoon Yolanda (Haiyan) & 8-Nov-2013 & 7,354 \\
\hline 1976 Mindanao earthquake & 17-Aug-1976 & 6,000 \\
\hline Typhoon Uring (Thelma) & 5-Nov-1991 & 5,956 \\
\hline 1990 Luzon earthquake & 16-Jul-1990 & 2,412 \\
\hline Typhoon Pablo (Bopha) & 4-Dec-2012 & 1,901 \\
\hline Tropical Depression Winnie & 29-Nov-2004 & 1,619 \\
\hline Typhoon Titang (Kate) & 13-Oct-1970 & 1,551 \\
\hline Typhoon Sendong (Washi) & 15-Dec-2011 & 1,439 \\
\hline Typhoon Nitang (Ike) & 1-Sep-1984 & 1,422 \\
\hline Typhoon Reming (Durian) & 30-Nov-2006 & 1,399 \\
\hline
\end{tabular}

models individuals make logical, reasoned decisions to engage in specific behaviours by evaluating the information available to them. In addition, the performance of a behaviour is determined by the individual's intention, which in turn is affected by one's attitude or value placed on the behaviour and subjective norms or views of other people in a family or community) and the perceived ease with which one can act on one's intentions or perception that the behaviour is within one's control. In a study which analysed the mechanism of risk perception and behaviour towards disaster risk of residents in Metro Manila, it was found that intention was predicted by attitude, subjective norms and risk perception, and risk aversive behaviour was predicted by intention [4]. Fishbein's theory of planned behaviour was followed by many studies also in the field of disaster research.

There are some studies based on Leyte related to risk perception and disaster risk reduction after Typhoon Haiyan. Lejano et al. [5] discussed about the risk perception through investigation of the role of risk communication. Tuhkanen et al. [6] discussed the risk perception of people after Haiyan in terms of trade-offs in development and disaster risk reduction. However, there are very few studies which have attempted to analyse the mechanisms involving risk perception, intention and structurally targeted risk reduction behaviour in post-Haiyan Leyte. Thus, this study aims to formulate a conceptual framework and then empirically investigate the interrelated nature of these mechanisms to understand the factors that affect risk perception of people after a major disaster like Typhoon Haiyan.

The importance of enhancing the resilience of communities vulnerable to natural hazards cannot be emphasized more in countries like the Philippines with limited resources for construction of state-of-the-art infrastructure or technology for disaster prevention. A possible approach towards community resilience is to foster each resident's adaptive behaviour towards natural hazards. In so doing, the capacity of each member of the community to engage in self-help and mutual help initiatives can potentially be increased. Adaptive behaviour is expressed as preparation for potential disasters by reducing identifiable risks. Individual or community-initiated risk reduction behaviour is assumed to be related to how people perceive disaster risks. Risk perception and engagement in risk reduction behaviour are affected by factors including disaster experiences, information, disaster knowledge and community coping as well as the capability to implement build-back better strategies. In this study, we clarify important factors affecting how people perceive 
disaster risks and conduct risk reduction behaviour. By doing so, we can ascertain whether current grassroots initiatives related to disaster education and community activities are effective in raising risk awareness and influencing risk-reduction behaviour of people to support the build-back-better process of their communities.

In this study, a behavioural intention model is developed to analyse factors of risk perception and disaster risk-reducing behaviour in high-risk areas (that is, natural hazards frequency of at least once in every 10-year cycle). A questionnaire survey was conducted in communities in Leyte to collect data to be used for the empirical analysis.

\section{CONCEPTUAL FRAMEWORK: BEHAVIOURAL INTENTION MODEL FOR DISASTER REDUCTION}

In this study, a behavioural intention model is conceptualized to analyse important factors affecting how people perceive disaster risks and intend to conduct adaptive behaviour to reduce disaster risks. Adaptive behaviour is defined as disaster risk reduction behaviour, such as preparing goods for emergency, planning for evacuation or building strong structure houses. We focus on two critical elements of (a) knowledge about disaster and (b) community efforts for disaster risk reduction in analysing how risk perception is related to risk reduction behaviour. Observed variables for disaster experiences and Demographic characteristics are included in the empirical analysis of factors that influence risk perception and preparedness through engaging in risk reduction behaviour.

\subsection{Factors affecting disaster preparedness and risk perception}

In developing the empirical model, we needed to identify the factors to be analysed. In the discussion with the local partner who helped conduct this survey, it was decided not to use the concept of subjective norms or normative beliefs in the questionnaire due to the potential implementation drawbacks and communication gaps between the enumerators and respondents. Thus, the model and factors were simplified to avoid misinterpretation of survey questions. Six factors are identified, which are "experiences of disaster", "Demographic characteristics", "risk perception", "knowledge", "intention for disaster preparedness" and "community efforts". In this study, risk perception is considered an important factor to link other factors in the model. Those factors are expressed as follows.

1) Disaster experience: Whether the respondent has previously experienced the occurrence of a natural disaster;

2) Demographic attributes: Age, sex, education, income;

3) Risk perception: The way one perceives risk of a natural disaster;

4) Intention: Behavioural intention of an individual's readiness to perform disaster risk reduction activities or behaviour;

5) Knowledge: Knowledge about natural hazards, disaster, or countermeasures related to natural hazard;

6) Community: Community efforts for disaster risk reduction.

\subsection{Hypothesis building and model formulation}

Previous disaster experiences are considered the most effective factor to affect risk perception of people according to recent studies by Bustillos Ardaya et al. [7], Lechowska [8]. It is postulated that risk perception is different depending on the degree or extent of damages or costs people incur. Risk perception is defined as how serious people understand and perceive 


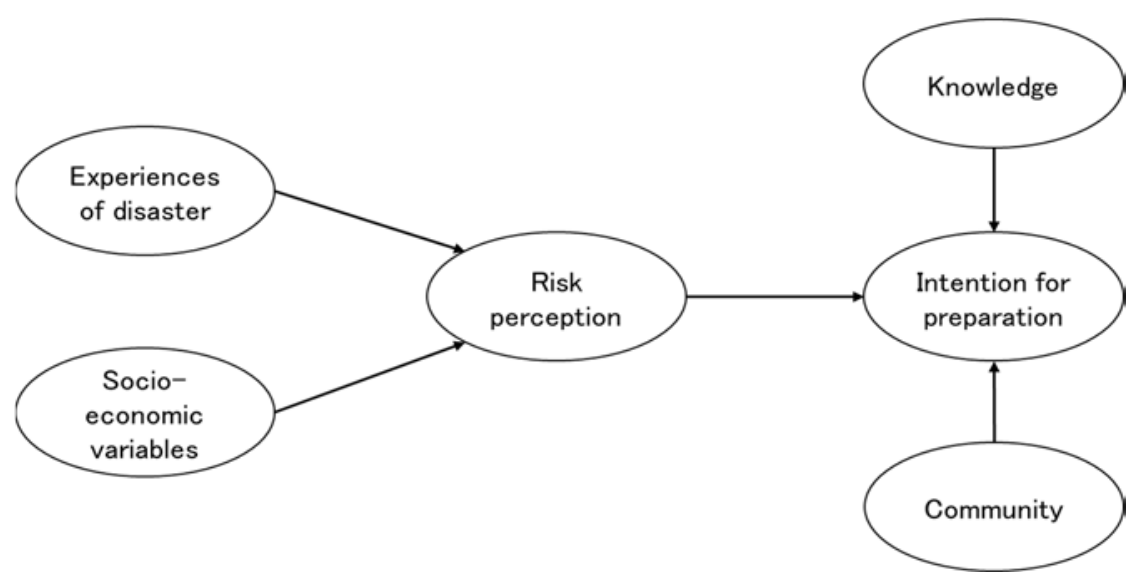

Figure 1: Behavioural intention model.

disaster risks in both positive and negative ways. Thus, it is expected to affect intention to conduct disaster risk reduction behaviour. Our study considers factors related to community initiatives based on behavioural intention model analysis of Paton [9]. Paton and Tedim [10] indicated community engagement affects intention to prepare for disaster risk reduction, which affects behaviour. In our study, the intention to conduct disaster risk reduction is also postulated to be affected by the level of knowledge about natural hazards of individuals and commitment to engage in efforts for disaster risk reduction as a community.

Hypotheses are formulated based on the assumption of reciprocal relations of factors as follows and the conceptual model of behavioural intention model is shown in Fig. 1.

1) Previous experience of disaster affects risk perception;

2) Demographic attributes of respondents affect risk perception;

3) Risk perception affects intention to engage in disaster risk reduction behaviour;

4) Community efforts to conduct disaster management affects individual disaster risk reduction behaviour;

5) Knowledge level of natural hazards affects disaster risk reduction behaviour.

\section{QUESTIONNAIRE SURVEY}

Questionnaire survey was conducted to collect data to analyse risk perception, intention for disaster risk reduction and related factors. Locations of barangays or communities were chosen from affected communities according to the degree of community-based commitment towards disaster risk reduction according to authors' evaluation and/or observation of community activities as well as upon consultation with barangay or local community leaders. Barangay is the "primary planning and implementing unit of government policies, plans, programs, projects, and activities in the community" located in contiguous territory of at least 2,000 inhabitants who elect the following officials (one barangay captain or "punong barangay", seven (7) sangguniang barangay members (barangay advisory council members), and one sangguniang kabataan (youth advisory council) chairman. There are also two appointive officials (secretary and treasurer). The sangguniang barangay council is tasked with forming the peace and order brigade or "lupong tagapamayapa" as well as other community brigades "deemed necessary to carry out the purposes of the Barangay government in accordance with the needs of public service" [11]. 


\subsection{Sampling areas}

Three heavily damaged communities in the cities of Tacloban, Palo and Tanauan located in the eastern coast of Leyte, Philippines are chosen as sampling areas. (See Fig. 2). More specifically, respondents in Tacloban are located in the district of Anibong (or Barangay 69); while those in Palo are residents of Barangay San Joaquin, and finally, respondents from Barangay Bislig in Tanauan comprise the sample of this survey.

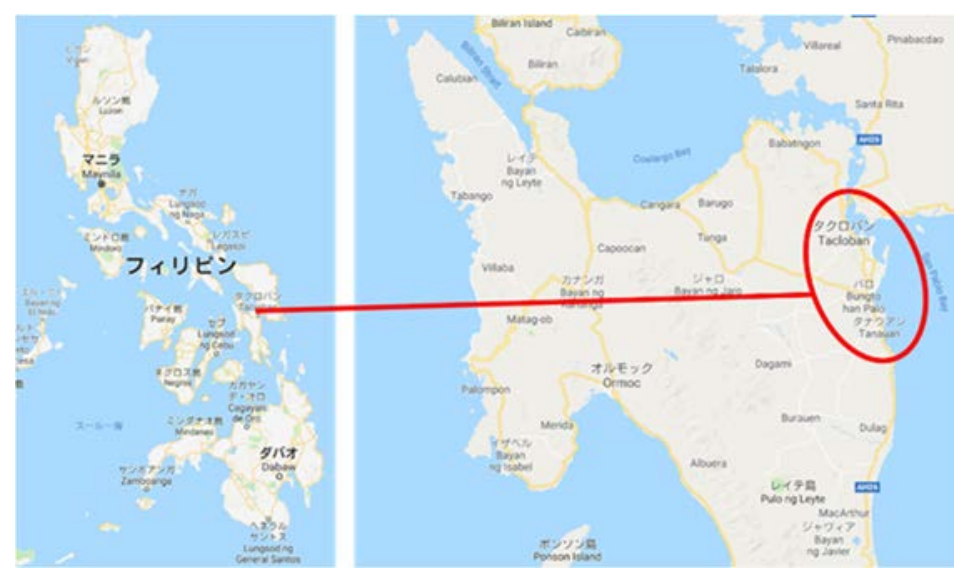

Figure 2: Geographic location of sampling areas. (Source: Google).

The sampling areas are categorized based on the level of disaster risk reduction commitment: (1) Anibong (Barangay 69), relatively high; (2) Barangay San Joaquin, moderate; and Barangay Bislig, relatively low. Sampling areas level of community-based commitment towards disaster risk reduction are summarized in Table 2.

Table 2: Characteristics of sampling areas.

\begin{tabular}{|l|l|l|l|}
\hline $\begin{array}{l}\text { Level of DRR } \\
\text { community commitment/ } \\
\text { description }\end{array}$ & Relatively high & Moderate & Relatively low \\
\hline Community & Brgy. 69 Anibong & Brgy. San Joaquin & Brgy. Bislig \\
\hline Municipality & Tacloban & Palo & Tanauan \\
\hline Main natural hazards & Storm surge & Storm surge & Flooding \\
\hline Drill pre-Haiyan & $\begin{array}{l}\text { Drills for various } \\
\text { hazards }\end{array}$ & No drills & No drills \\
\hline Drill post-Haiyan & $\begin{array}{l}\text { Quarterly drills for } \\
\text { various hazards }\end{array}$ & Once a year & Being planned \\
\hline $\begin{array}{l}\text { DRR Program } \\
\text { developments }\end{array}$ & $\begin{array}{l}\text { Community hazard } \\
\text { map, Community } \\
\text { prioritization gas } \\
\text { provision for } \\
\text { emergency }\end{array}$ & $\begin{array}{l}\text { Construction of } \\
\text { evacuation center }\end{array}$ & $\begin{array}{l}\text { Expansion of } \\
\text { Barangay hall } \\
\text { (Budget on } \\
\text { request) }\end{array}$ \\
\hline
\end{tabular}




\subsection{Survey method}

Questionnaires were prepared to collect data pertaining to the hypotheses formulated in Section 2.2. For the latent variable of "demographic attributes", "sex", "age", and "education" were chosen as measurable variables. For the latent variable of "disaster experiences", we asked respondents whether they or their families incurred damages to properties and/or injuries. For latent variable of "risk perception", we asked how likely they think a strong typhoon like Haiyan will happen again in the future and psychological factors such as recurring memories or visual images in flashbacks or nightmares or feelings of trauma related to Haiyan. For latent variable of "intention", variables to measure the intention of a respondent to conduct disaster risk reduction behaviour by him/herself or with other members of the community. In this study, adaptive behaviour itself is not approached directly, but the intention is measured instead because respondents are still in the early years of the recovery process, and it takes more time until the adaptive behaviour is planned and put into action. For the latent variable of "knowledge", variables to measures provisions for disaster education by individuals before and after typhoon Yolanda", and awareness of the word "storm surge" were chosen. Finally, for the latent variable "community", variables measuring community efforts to practice evacuation drills and construct facilities for disaster reduction were chosen. Measurable variables for each latent variable are summarized in Table 3.

Table 3: Description of variables.

\begin{tabular}{|c|c|c|}
\hline Latent variables & $\begin{array}{l}\text { Measurable } \\
\text { variables }\end{array}$ & Description \\
\hline \multirow[b]{2}{*}{$\begin{array}{l}\text { Disaster } \\
\text { experience }\end{array}$} & Injury & Whether respondent was injured by typhoon Haiyan \\
\hline & $\begin{array}{l}\text { Loss of family } \\
\text { members }\end{array}$ & $\begin{array}{l}\text { Whether respondent lost families by typhoon } \\
\text { Haiyan }\end{array}$ \\
\hline \multirow{3}{*}{$\begin{array}{l}\text { Demographic } \\
\text { attributes }\end{array}$} & Sex & Sex of respondent \\
\hline & Age & Age of respondent \\
\hline & Education & Highest education a respondent has \\
\hline \multirow{3}{*}{ Risk perception } & $\begin{array}{l}\text { Perceived } \\
\text { likelihood of } \\
\text { recurrence }\end{array}$ & $\begin{array}{l}\text { The extent a respondent thinks a strong typhoon } \\
\text { will happen again }\end{array}$ \\
\hline & Flashback & $\begin{array}{l}\text { A respondent remembers images (in flashbacks } \\
\text { and/or nightmares) of the typhoon }\end{array}$ \\
\hline & Stress/trauma & $\begin{array}{l}\text { Whether a respondent feel trauma when he/she } \\
\text { thinks about the typhoon }\end{array}$ \\
\hline \multirow[b]{2}{*}{ Intention } & Int_you & $\begin{array}{l}\text { The extent of a respondent's intention to conduct } \\
\text { disaster risk reduction behaviour by him/herself }\end{array}$ \\
\hline & Int_com & $\begin{array}{l}\text { The extent of a respondent's intention to conduct } \\
\text { disaster risk reduction behaviour through mutual } \\
\text { help in the community }\end{array}$ \\
\hline \multirow{3}{*}{ Knowledge } & Dis_ed_bef & Disaster education before typhoon Haiyan \\
\hline & Dis_ed_aft & Disaster education after typhoon Haiyan \\
\hline & Storm surge & Knew the word "storm surge" before Haiyan \\
\hline \multirow[b]{2}{*}{ Community } & Community & Community evacuation drill \\
\hline & Community & $\begin{array}{l}\text { Construction of disaster management facilities in } \\
\text { the community }\end{array}$ \\
\hline
\end{tabular}


Survey implementation activities were conducted during the period of October 1 to 12 in 2018. The tasks of the survey enumerators were to (1) visit households in each barangay; (2) interview the household head or his/her representative; and, (3) write down the responses and other notes. One person per household were sampled from barangays located near the coast. Households were randomly chosen by the enumerators with the help of barangay or community leaders who knew which households belonged to which barangay. Approximately 100 sample observations were collected from each barangay. After cleaning the data, the valid observations totalled 282 with the following breakdown: 92 in Anibong, Tacloban; 99 in San Joaquin, Palo; and, 91 in Bislig, Tanauan.

\section{ANALYSIS AND FINDINGS}

Based on the conceptual framework described in Section 3, a structural equation model (SEM) is applied to empirically test the behavioural intention model. After several iterations, we obtained results shown in Fig. 3. The Chi-square statistic is 41.758 and CMIN/DF is 2.198. The overall model fit is a GFI value of 0.965 , AGFG value of 0.933 , and RMSEA value of 0.65 . These represent goodness of fit in the specified structural equation model.

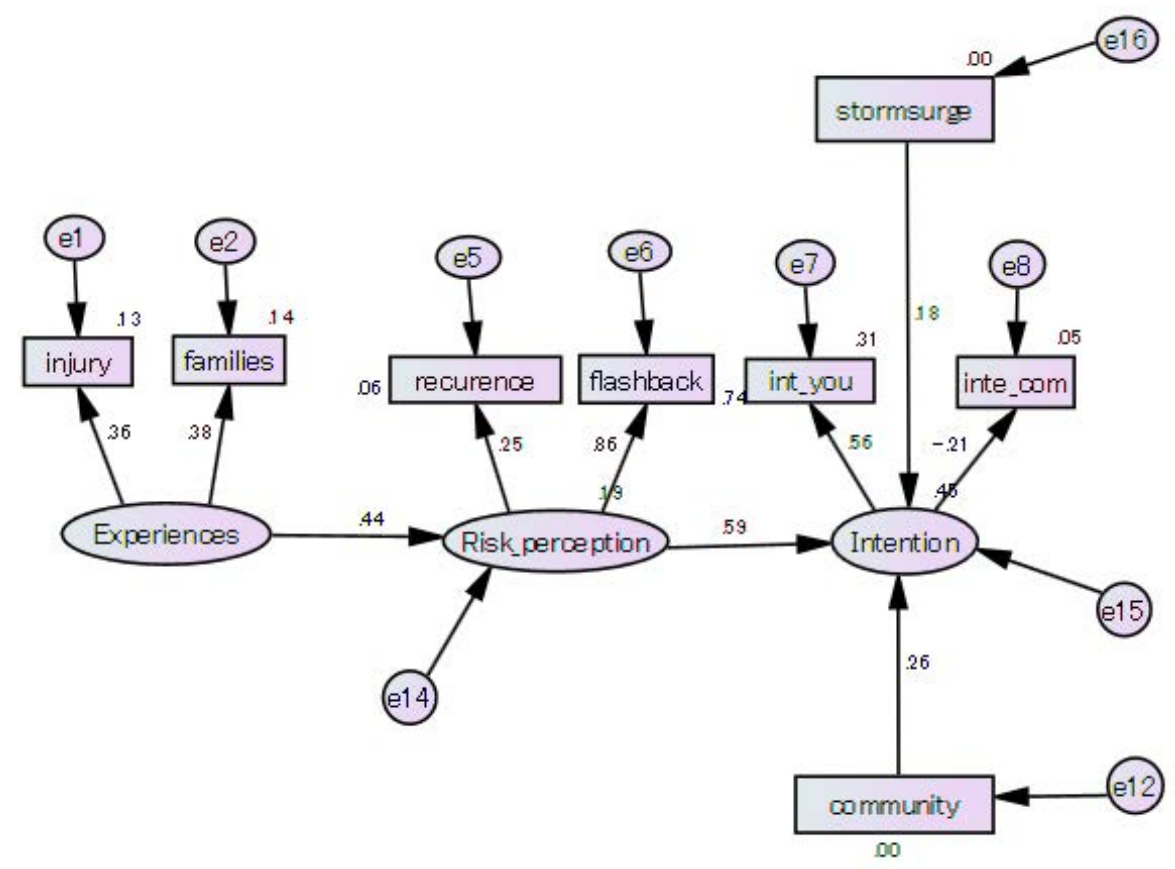

Figure 3: Structural equation modelling (SEM) analytical results.

\subsection{Influences of intention to conduct disaster risk reduction behaviour}

The results show that the variable for "experiences" affects "risk perception" significantly which in turn affects the individual's "intention to conduct disaster risk behaviour" significantly. The measured variables of "injury" and "loss of families" (for the latent variable of "disaster experiences") influence "risk perception" with relative significance. Measurable variables of the latent variable "demographic attributes", such as "age", "sex" 
and "education" did not affect "risk perception" in this model, and the goodness of fit of the model was not satisfactory, thus, latent variable "demographic attributes" were eliminated from the final model.

Simulation of the measurable variables of "risk perception" ("recurrence" and "flashback") yielded highly significant coefficients which imply compatibility of the model and significant influence on "intention". Especially, "flashback" accounts for "risk perception", and it indicates that people who responded that they do not want to be reminded about Haiyan but still have flashbacks or nightmares about it are more likely to have the intention to conduct disaster risk reduction behaviour. It means that people who take risks more seriously and feel some anxiety tend to have the intention to conduct disaster risk reduction behaviour. Although the level of significance of the coefficient of "recurrence" accounting for "risk perception" is low, it means that people who think strong typhoon like Haiyan will occur again in the near future tend to have intention to conduct disaster risk reduction behaviour strongly. The flipside of the coin implies that people who perceive low risks of a strong typhoon like Haiyan occurring again soon, tend to have no intention to conduct disaster risk reduction behaviour.

"Intention" explained by measurable variables "int_you" and "int_com" yields compatibility of the model and statistically significant coefficients. Coefficients accounting for "intention" of "Int_you" are relatively large and that of "int_com" is negative. It indicates that people who are capable of self-help or initiating disaster management activities tend to have intention for risk reduction behaviour while people who expect help from the community are less likely to have the intention to engage in disaster risk reduction behaviour.

Table 4: Significance of path coefficients.

\begin{tabular}{|l|c|}
\hline Measurable and latent variables & $P$-values \\
\hline Risk_perception $<---$ Experiences & $0.438(p<.05)$ \\
\hline Intention $<---$ community & $0.263(p<.01)$ \\
\hline Intention $<---$ risk_perception & $0.594(p<.01)$ \\
\hline Intention $<---$ stormsurge & $0.183(p<.1)$ \\
\hline Injury $<---$ experiences & $0.356(p<.05)$ \\
\hline Families $<---$ experiences & $0.377(p<.1)$ \\
\hline Recurrence $<---$ risk_perception & $0.252(p<.05)$ \\
\hline Flashbacks $<---$ risk_perception & $0.859(p<.01)$ \\
\hline Int_you $<---$ intention & $0.558(p<.05)$ \\
\hline Int_com $<---$ intention & $-0.213(p<.05)$ \\
\hline
\end{tabular}

\subsection{Effects of knowledge and community efforts}

Based on the empirical results, "knowledge" and "community disaster risk reduction" have relatively small marginal effects on the individual's "intention to conduct disaster risk behaviour". Analysis of the model using the latent variable "knowledge" with measurable manifestations such as disaster-related "education before Haiyan" and "education after Haiyan" did not yield statistically significant coefficients. However, the results for the observed variable of "(pre-Haiyan) knowledge about storm surge" were highly significant which imply compatibility with the behavioural intention model. The above explains that "disaster experiences" as well as "knowing about storm surges (or other natural hazards)" strongly affect "risk perception". 


\section{CONCLUSION}

We formulated a behavioural intention model built on the hypothesis that having previous disaster experience affects risk perception which in turn affects the intention to engage in disaster risk behaviour. We empirically test this behavioural intention model using data collected from Tacloban, Palo and Tanuan in Leyte, Philippines. We find that previous disaster experiences positively increase awareness or enhance risk perception that lead to adaptive behaviour for disaster risk reduction suitable for building-back better process. Moreover, although influences of knowledge and community efforts for disaster reduction were not observed significant at this time, it is necessary to continue efforts to provide disaster knowledge and involve people in community-based disaster risk reduction activities as it takes time to see effects of those efforts in the long-term process of building-back better and resilient communities.

\section{ACKNOWLEDGEMENTS}

We are grateful to the staff and residents of the barangays for their cooperation in the questionnaire survey. The results of this study will be shared with the barangays as a resource for building resilient communities in Leyte. We also express our appreciation to Japan's Ministry of Education and Hyogo Prefecture for providing research funds for this study.

\section{REFERENCES}

[1] EM-DAT: The Emergency Events Database. Universite Catholique de Louvain (UCL), CRED, D. Guha-Sapir. www.emdat.be, Brussels.

[2] Fishbein, M. \& Ajzen, I., Belief, Attitude, Intention and Behavior: An Introduction to Theory and Research. Addison-Wesley: Reading, MA, 1975.

[3] Ajzen, I. \& Fishbein, M., Understanding Attitudes and Predicting Social Behavior. Prentice-Hall, Inc: Englewood Cliffs, 1980

[4] Tatsuki, S. et. al., The impact of risk perception, disaster scheme, resources, intention, attitude, and norms upon risk aversive behavior among Marikina City residents: Structural equation modelling with latent variables. Proceedings of Asia Conference on Earthquake Engineering, vol. 1, pp. 267-272, 2004.

[5] Lejano, R. et. al., Communicating risk: Learning from Typhoon Haiyan. Nature, 518(7537), p. 35, 2015.

[6] Tuhkanen, H. et al., A typology framework for trade-offs in development and disaster risk reduction: A case study of typhoon Haiyan recovery in Tacloban, Philippines. Sustainability, 10(6), 2018.

[7] Bustillos Ardaya, A., Eversa, M. \& Ribbe, L., What influences disaster risk perception? Intervention measures, flood and landslide risk perception of the population living in flood risk areas in Rio de Janeiro state, Brazil. International Journal of Disaster Risk Reduction, pp. 227-237, 2017.

[8] Lechowska, E., What determines flood risk perception? A review of factors of flood risk perception and relations between its basic elements. Natural Hazards, 94(3), pp. 1341-1366, 2018.

[9] Paton, D., Disaster preparedness: A social cognitive perspective. Disaster Prevention and Management, 12(3), 2003.

[10] Paton D. \& Tedim, F., Enhancing forest fires preparedness in Portugal: Integrating community engagement and risk management. Planet at Risk, 1(1), 2013.

[11] Philippine Local Government Code of 1991, Official Gazette. www.officialgazette.gov.ph/downloads/1991/10oct/19911010-RA-7160-CCA.pdf. Accessed on: 8 Jul. 2019. 